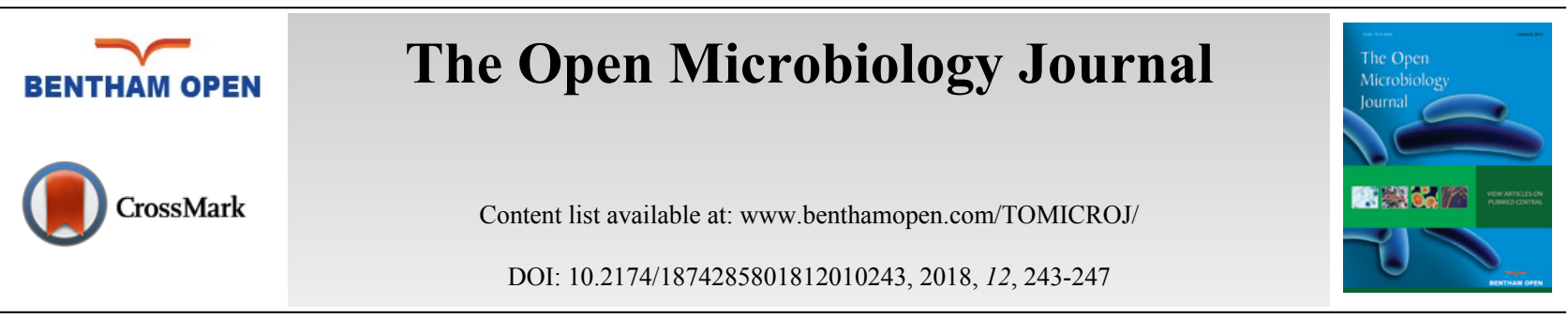

CASE REPORT

\title{
Nontypable Haemophilus influenzae Septicemia and Urinary Tract Infection Associated with Renal Stone Disease
}

\author{
Marianne Stærk $^{1}$, Sara A. Tolouee ${ }^{2}$ and Jens J. Christensen ${ }^{1,3, *}$ \\ ${ }^{I}$ Department of Clinical Microbiology, Slagelse Hospital, Slagelse, Denmark \\ ${ }^{2}$ Department of Urology, Zealand University Hospital Roskilde, Roskilde, Denmark \\ ${ }^{3}$ Institute of Clinical Medicine, University of Copenhagen, Copenhagen, Denmark
}

Received: March 31, 2018

Revised: July 10, 2018

Accepted: July 15, 2018

\begin{abstract}
:
Introduction:

Haemophilus influenzae commonly causes upper respiratory tract infections and has only rarely been reported etiology of urinary tract infections. Since the introduction of the Haemophilus influenzae b (Hib) vaccine, non-typable haemophilus species now cause the majority of invasive disease in Europe.
\end{abstract}

\section{Case Report:}

We report a case of an adult man with non-typable Haemophilus influenzae septicemia, urinary tract infection and bilateral renal stone disease. The patient presented with right sided flank pain and a CT scan showed bilateral renal stones and a right sided ureteral stone causing obstruction.

\section{Results and Discussion:}

Haemophilus influenzae was identified in blood and urine and despite a tendency of increasing antibiotic resistance among Haemophilus influenzae, our strain was susceptible to all antibiotics tested. Treatment consisted of 3 days of intravenous cefuroxime, insertion of a right sided JJ ureteric stent and 5 days of peroral ciprofloxacin after discharge. Physicians and microbiologists should be aware of Haemophilus influenzae as a possible urinary tract pathogen, especially when urinary tract abnormalities are present, and take the risk of antibiotic resistance into consideration at initial treatment.

Keywords: Hemophilus influenzae infection, Invasive disease, Urinary tract infection, Renal stones, Non-typable, Antibiotic resistance.

\section{INTRODUCTION}

Haemophilus influenzae is reported as a rare urinary tract pathogen in adults [1 - 5]. It is a small gram-negative rod and part of the normal bacterial flora in the human upper respiratory tract; strains may possess a polysaccharide capsule or be non-capsulated. The capsular strains are divided into six serotypes (a-f) based on their polysaccharide capsule whereas the non-capsular lack the polysaccharide capsule and are often less virulent. $H$. influenzae species usually causes upper respiratory tract infections, otitis media, pneumonia and exacerbation of chronic obstructive pulmonary disease. Less frequently, they give rise to invasive disease such as sepsis and meningitis [6,7]. Here, we report a case of septicemia with a non-capsulated H. influenzae strain isolated from blood and urine in a 32-year old man with bilateral renal stones.

\footnotetext{
* Address correspondence to this author at the Department of Clinical Microbiology, Slagelse Hospital, 4200 Slagelse, Denmark; Tel: +4558559404; E-mail: jejc@regionsjaelland.dk
} 


\section{CASE REPORT}

A 32-year old man was admitted to a Danish hospital due to right sided flank pain of four days duration. He had no confirmed medical diagnoses, but had previously been tested for Sarcoidosis, Polycythemia vera, stroke and acute coronary syndrome. He also had a history of former steroid-use. The available medical records did not state his vaccination status or previous childhood infections. At hospitalization, he presented with intermittent right sided flank pain, turning into constant pain of VAS 7-8 and radiating to the right side groin. Additional symptoms were nausea, chills, and observation of blood in the urine. Physical examination revealed right sided abdominal and renal pain and a temperature of 38.0 degrees Celsius. His urine tested positive for leucocytes, erythrocytes, nitrite and protein $1 \mathrm{~g} / \mathrm{L}$ and blood samples showed normal urate levels, elevated ionized calcium levels $1.56 \mathrm{mmol} / \mathrm{L}$, creatinine $122 \mu \mathrm{mol} / \mathrm{L}$, leukocytosis of $15.9 \times 10^{9} / \mathrm{L}$ and CRP $6.4 \mathrm{mg} / \mathrm{L}$ increasing to $172 \mathrm{mg} / \mathrm{L}$ the next day. CT scan showed bilateral nephrolithiasis as well as right side ureterolithiasis causing obstruction Fig. (1). Direct microscopy on three out of three blood culture bottles revealed small gram-negative pleomorphic rods within 24 hours of incubation. Mass spectrometry (Bruker Daltonics using MBT Compass software version 4.1 that contains 6903 MSP's) identified the strain as $H$. influenzae with a score of 2.24. Microbiology testing of urine routinely cultured on a 5\% blood agar plate and a UTI chrome agar plate showed $10^{5}$ growth of $H$. influenzae confirmed by MALDI-TOF MS (score of 2.15). The strain was found to be a non-capsulated biotype II, susceptible to all antibiotics tested by disc diffusion: penicillin ( 1 unit, zone diameter: blood $=15 \mathrm{~mm}$, urine $=15 \mathrm{~mm})$, amoxicillin-clavulanate $(3 \mu \mathrm{g})$, ampicillin $(10 \mu \mathrm{g})$, ciprofloxacin $(5 \mu \mathrm{g}$, zone diameter: blood $=35 \mathrm{~mm}$, urine $=41 \mathrm{~mm})$, cefuroxime $(30 \mu \mathrm{g})$ and piperacillin-tazobactam $(36 \mu \mathrm{g})$ using EUCAST disc diffusion recommendations. After microbiology samples had been collected, the patient started antibiotic treatment with intravenous ampicillin $1 \mathrm{~g} \mathrm{x} 4$ daily and a right sided JJ ureteric stent was surgically inserted. The patient received two doses of ampicillin, but due to subjective discomfort, treatment was changed to cefuroxime $1500 \mathrm{mg}$ x 3 daily. After three days, the patient was discharged with 5 days of peroral ciprofloxacin $500 \mathrm{mg}$ x 2 and a scheduled ambulant stone-removal surgery.

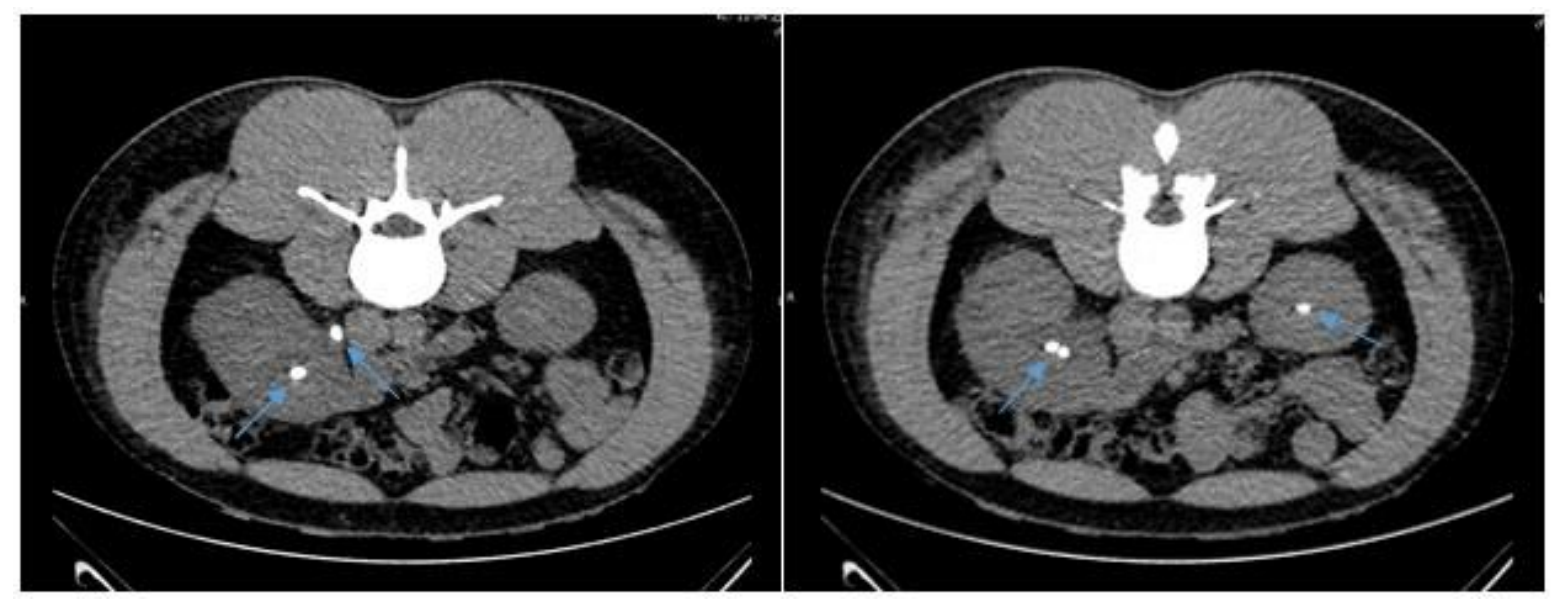

Fig. (1). Computed Tomography (CT) scan showing bilateral renal calculi and right sided ureteral calculus (arrows).

\section{DISCUSSION}

H. influenzae Invasive Bacterial Disease (IBD) has especially been related to encapsulated strains, mainly serotype b strains causing septicemia, meningitis or epiglottitis. After introduction of Hib vaccination in the childhood vaccine program, episodes with meningitis and epiglottitis have declined to very few cases annually in Denmark [8]. Invasive disease caused by encapsulated strains belonging to other serotypes do occur. However, there is an increasing trend of infections due to non-capsular strains. Hib vaccination does not give protection against infection with such strains. The latest Epidemiological Report, made by the European Centre for Disease Prevention and Control (ECDC), states that in 2014, 2799 confirmed $H$. influenzae IBD cases were reported (29 countries) [8]. When dividing by serotype it was found that by far the greatest number of cases were caused by non-capsular strains in all age groups (1706 cases, 20 countries) [8]. The highest rates of invasive disease were in children $<1$ year old and the elderly with the age of $>65$ years, thus, age groups more prone to infectious disease [8]. The most common clinical presentation in this post-Hib vaccine era is pneumonia and septicemia $[8,9]$. Our case however was a young immunocompetent man with a urinary tract infection and septicemia. Seldomly, cases of $H$. influenzae invasive disease with recognized foci outside the 
respiratory tract occurs. $H$. influenzae has been reported as the causative agent of acute pyelonephritis [2, 3], chronic prostatitis [10], endometritis [11] and the $H$. influenzae species has been isolated from urethra in men with symptomatic urethritis [4]. During a 15-year study period, Christensen J.J. et al. isolated Haemophilus species from different unusual sites such as gynaecological or gastrointestinal sites as well as soft tissue and bone and muscle tissue [12]. Specimens from 80 patients were included and 17 isolates were in pure culture. Nine of these were from the Bartholin's glands, salpinges or parametrium.

In this case, non-typable $H$. influenzae biotype II was isolated from blood and urine and associated with renal stone disease in a young male patient. He had no respiratory symptoms or alternative focus. Usually, urinary tract infections are caused by Enterobacteriaceae such as E.coli, Klebsiella, Proteus and Serratia species, and less frequently Pseudomonas aeruginosa. Fujii et al. recently reported a similar case of a 46-year old man with biotype III bacteremic pyelonephritis and unilateral ureteral stone [3]. In children, H. influenzae urinary tract infections are rare and possibly associated with abnormalities of the urinary tract $[13,14]$. A retrospective study, over a 24-year period, found 36 children out of 5000 urinary tract episodes, with $H$. influenzae or H. parainfluenzae bacteriuria, equivalent to $<1 \%$ of the episodes, and the majority of the children had a urinary tract abnormality and/or renal damage [13]. Thus, we argue that $H$. influenzae urinary tract infections could be associated with urinary tract or renal disease in adults, as well as children. A proposed link between stone disease and $H$. influenzae bacteriuria could be the urease activity of the bacteria resulting in ammonia synthesis. This increases the $\mathrm{pH}$ of the urine and possibly creates a more favorable environment for bacterial growth as well urolithiasis formation [15]. In addition, it has been demonstrated that nontypable $H$. influenzae from clinical isolates are able to form biofilm [16] which may increase the risk of chronic infection, facilitate further urolithiasis and increase the resistance to antibiotic treatment.

The isolated strain in our case was susceptible to all antibiotics tested with no recognized resistance mechanisms present. However, the emerging antibiotic resistance in recent years against ampicillin and several other antibiotics among strains of $H$. influenzae gives cause for serious concern $[17,18]$. Epidemiological studies indicated that $8 \%$ to $30 \%$ of isolates in Europe and North America, and up to around 50\% of isolates in East Asia were resistant to ampicillin [17 - 19]. The recognized resistance mechanisms are beta-lactamase production and PBP3 alterations by mutation [17, 20]. A Korean study of 540 isolates from respiratory tract infections, predominantly non-typable, showed ampicillin resistance of $58 \%$ and beta-lactamase production in $52.4 \%$ of the isolates [17]. In Canada, a study of 882 isolates of invasive disease demonstrated an increase in beta-lactamase production from 2007 to 2014 and an increasing trend of significant PBP3 mutations [20]. Therefore, when recognizing a serious invasive infection caused by a $H$. influenzae strain the possibility of eventual antibiotic resistance has to be taken into consideration in the initial treatment recommendation.

Growth of $H$. influenzae requires growth factor X (heme) and factor V (NAD). For their detection, it is crucial using culture methods accommodating these needs, which is not always done when examining urine specimens. This may lead to an underestimation of occurrence of $H$. influenzae in urine samples. In our case identification was done using MALDI-TOF mass spectrometry. In a recent study on identification of respiratory pathogens, including $64 H$. influenzae strains, by conventional phenotypic methods and mass spectrometry [21], it was shown that mass spectrometry provides identification of these bacteria faster and in a more reliable way than those based on conventional phenotypical methods [21].

\section{CONCLUSION}

To our knowledge, this is the first European report on non-capsulated H. influenzae as etiology of an invasive urinary tract infection associated with renal stones in an immunocompetent young adult. In this post-Hib vaccine era, non-capsulated $H$. influenzae strains causes the majority of invasive $H$. influenzae infections. $H$. influenzae may be an underestimated cause of urinary tract infections and should be kept in mind in culture-negative urinary tract infections, especially when urinary tract abnormalities are present. The emerging antibiotic resistance in recent years against ampicillin and several other antibiotics among strains of $H$. influenzae has to be taken into consideration when determining initial antibiotic treatment of invasive disease.

\section{ETHICS APPROVAL AND CONSENT TO PARTICIPATE}

Not applicable. 


\section{HUMAN AND ANIMAL RIGHTS}

Not applicable.

\section{CONSENT FOR PUBLICATION}

A written informed consent for publication was obtained.

\section{CONFLICT OF INTEREST}

The authors declare no conflict of interest, financial or otherwise.

\section{ACKNOWLEDGEMENTS}

Declared none.

\section{REFERENCES}

[1] de Almeida AECC, Caldeira NGS, Schroeder LFL, et al. Urinary tract infection caused by nontypable Haemophilus influenzae in the elderly. J Med Microbiol 2010; 59(Pt 9): 1132-3. Available from: http://jmm.microbiologyresearch.org/content/journal/jmm/10.1099/jmm.0.019224-0 [http://dx.doi.org/10.1099/jmm.0.019224-0] [PMID: 20576753]

[2] Demetrios P, Constantine B, Demetrios S, Nikolaos A. Haemophilus influenzae acute pyelonephritis in the elderly. Int Urol Nephrol 2002; 34(1): 23-4. Available from: http://www.ncbi.nlm.nih.gov/pubmed/12549634 [http://dx.doi.org/10.1023/A:1021316308674] [PMID: 12549634]

[3] Fujii M, Gomi H, Ishioka H, Takamura N. Bacteremic renal stone-associated urinary tract infection caused by nontypable Haemophilus influenzae: A rare invasive disease in an immunocompetent patient. IDCases 2016; 7: 11-3. [http://dx.doi.org/10.1016/j.idcr.2016.11.005] [PMID: 27920983]

[4] Deza G, Martin-Ezquerra G, Gómez J, Villar-García J, Supervia A, Pujol RM. Isolation of Haemophilus influenzae and Haemophilus parainfluenzae in urethral exudates from men with acute urethritis: A descriptive study of 52 cases. Sex Transm Infect 2016; 92(1): 29-31. Available from: http://www.ncbi.nlm.nih.gov/pubmed/26139207 [http://dx.doi.org/10.1136/sextrans-2015-052135] [PMID: 26139207]

[5] Gabre-Kidan T, Lipsky BA, Plorde JJ. Hemophilus influenzae as a cause of urinary tract infections in men. Arch Intern Med 1984; 144(8): 1623-7. Available from: http://www.ncbi.nlm.nih.gov/pubmed/6331807 [http://dx.doi.org/10.1001/archinte.1984.00350200131019] [PMID: 6331807]

[6] Resman F, Ristovski M, Ahl J, et al. Invasive disease caused by Haemophilus influenzae in Sweden 1997-2009; evidence of increasing incidence and clinical burden of non-type b strains. Clin Microbiol Infect 2011; 17(11): 1638-45. Available from: http://www.ncbi.nlm.nih.gov/pubmed/21054663 [http://dx.doi.org/10.1111/j.1469-0691.2010.03417.x] [PMID: 21054663]

[7] Cleland G, Leung C, Wan Sai Cheong J, Francis J, Heney C, Nourse C. Paediatric invasive Haemophilus influenzae in Queensland, Australia, 2002-2011: Young Indigenous children remain at highest risk. J Paediatr Child Health 2017. Available from: http://doi.wiley.com/10.1111/jpc. 13662

[8] European Centre for Disease Prevention and Control. Invasive Haemophilus influenzae - Annual Epidemiological Report 2016. Available from: https://ecdc.europa.eu/en/publications-data/haemophilus-influenzae-disease-annual-epidemiological-report-2016-2014-data

[9] Sarangi J, Cartwright K, Stuart J, Brookes S, Morris R, Slack M. Invasive Haemophilus influenzae disease in adults. Epidemiol Infect 2000; 124(3): 441-7.

[http://dx.doi.org/10.1017/S0950268899003611] [PMID: 10982068]

[10] Al-Mohizea MM, Alotaibi FE. An unusual case of chronic prostatitis caused by Haemophilus influenzae in an elderly Saudi patient: A case report and literature review. J Family Community Med 2014; 21(3): 193-5. [http://dx.doi.org/10.4103/2230-8229.142975] [PMID: 25374472]

[11] Martin D, Dbouk RH, Deleon-Carnes M, del Rio C, Guarner J. Haemophilus influenzae acute endometritis with bacteremia: Case report and literature review. Diagn Microbiol Infect Dis 2013; 76(2): 235-6. [http://dx.doi.org/10.1016/j.diagmicrobio.2013.02.010] [PMID: 23537790]

[12] Christensen JJ, Kirkegaard E, Korner B. Haemophilus isolated from unusual anatomical sites. Scand J Infect Dis 1990; $22(4)$ : 437-44. Available from: http://www.ncbi.nlm.nih.gov/pubmed/2218406 [http://dx.doi.org/10.3109/00365549009027075] [PMID: 2218406]

[13] Hansson S, Svedhem A, Wennerström M, Jodal U. Urinary tract infection caused by Haemophilus influenzae and Haemophilus parainfluenzae in children. Pediatr Nephrol 2007; 22(9): 1321-5. [http://dx.doi.org/10.1007/s00467-007-0531-1] [PMID: 17541792]

[14] Allard L, Joly-Guillou ML, Champion G. Haemophilus influenzae urinary infection in 3 children with urinary shaft malformation Urinary tract infection caused by Haemophilus influenzae in 3 children with uropathies. Arch Pediatr 2012; 19(8): 842-6.

[http://dx.doi.org/10.1016/j.arcped.2012.05.016] [PMID: 22795780] 
[15] Murphy TF, Brauer AL. Expression of urease by Haemophilus influenzae during human respiratory tract infection and role in survival in an acid environment. BMC Microbiol 2011; 11(1): 183. Available from: http://www.biomedcentral.com/1471-2180/11/183 [http://dx.doi.org/10.1186/1471-2180-11-183] [PMID: 21843372]

[16] Qin L, Kida Y, Ishiwada N, et al. The relationship between biofilm formations and capsule in Haemophilus influenzae. J Infect Chemother 2014; 20(3): 151-6. [http://dx.doi.org/10.1016/j.jiac.2013.06.001] [PMID: 24560562]

[17] Bae S, Lee J, Lee J, et al. Antimicrobial resistance in Haemophilus influenzae respiratory tract isolates in Korea: Results of a nationwide acute respiratory infections surveillance. Antimicrob Agents Chemother 2010; 54(1): 65-71. [http://dx.doi.org/10.1128/AAC.00966-09] [PMID: 19884366]

[18] Jacobs MR. Worldwide trends in antimicrobial resistance among common respiratory tract pathogens in children. Pediatr Infect Dis J 2003; 22(8)(Suppl.): S109-19. Available from: http://www.ncbi.nlm.nih.gov/pubmed/14566997 [http://dx.doi.org/10.1097/00006454-200308001-00002] [PMID: 14566997]

[19] Hotomi M, Fujihara K, Billal DS, et al. Genetic characteristics and clonal dissemination of beta-lactamase-negative ampicillin-resistant Haemophilus influenzae strains isolated from the upper respiratory tract of patients in Japan. Antimicrob Agents Chemother 2007; 51(11): 3969-76. Available from: http://aac.asm.org/cgi/doi/10.1128/AAC.00422-07 [http://dx.doi.org/10.1128/AAC.00422-07] [PMID: 17698631]

[20] Tsang RSW, Shuel M, Whyte K, et al. Antibiotic susceptibility and molecular analysis of invasive Haemophilus influenzae in Canada, 2007 to 2014. J Antimicrob Chemother 2017; 72(5): 1314-9. [PMID: 28137937]

[21] López-Fabal MF, Gómez-Garcés JL, López-Hontangas JL, Sanz N, Muñoz C, Regodón M. Vitek MS matrix-assisted laser desorption ionization-time of flight mass spectrometry for identifying respiratory bacterial pathogens: A fast and efficient method 2015; 28(5): $242-6$. Available from: http://www.ncbi.nlm.nih.gov/pubmed/26437754

\section{(C) 2018 Stærk et al.}

This is an open access article distributed under the terms of the Creative Commons Attribution 4.0 International Public License (CC-BY 4.0), a copy of which is available at: (https://creativecommons.org/licenses/by/4.0/legalcode). This license permits unrestricted use, distribution, and reproduction in any medium, provided the original author and source are credited. 